\title{
Discordant nodal staging identifies intermediate-risk group for overall survival in patients with $\mathrm{CT} 3$ oesophageal adenocarcinoma
}

\author{
Charles Carder ${ }^{1} \cdot$ Patrick Fielding $^{2} \cdot$ Ashley Roberts $^{1} \cdot$ Kieran Foley $^{3,4}$ (D
}

Received: 20 November 2019 / Revised: 11 December 2019 / Accepted: 17 December 2019 / Published online: 13 February 2020

(C) The Author(s) 2020

\begin{abstract}
Objectives Oesophageal adenocarcinoma has a poor prognosis and relies on multi-modality assessment for accurate nodal staging. The aim of the study was to determine the prognostic significance of nodal concordance between PET/CT and EUS in oesophageal adenocarcinoma.

Methods Consecutive patients with oesophageal adenocarcinoma staged between 2010 and 2016 were included. Groups comprising concordant node-negative $(\mathrm{C}-\mathrm{ve})$, discordant (DC), and concordant node-positive (C+ve) patients were analysed. Survival analysis using log-rank tests and Cox proportional hazards model was performed. The primary outcome was overall survival. A $p$ value $<0.05$ was considered statistically significant.

Results In total, 310 patients (median age $=66.0$; interquartile range 59.5-72.5, males $=264$ ) were included. The median overall survival was 23.0 months (95\% confidence intervals (CI) 18.73-27.29). There was a significant difference in overall survival between concordance groups $\left(X^{2}=44.91, \mathrm{df}=2, p<0.001\right)$. The hazard ratios for overall survival of $\mathrm{DC}$ and $\mathrm{C}+\mathrm{ve}$ patients compared with those of C-ve patients with cT3 tumours were 1.21 (95\% CI 0.81-1.79) and 1.79 (95\% CI 1.23-2.61), respectively. On multivariable analysis, nodal concordance was significantly and independently associated with overall survival (HR $1.44,95 \%$ CI $1.12-1.83, p=0.004$ ) and performed better than age at diagnosis (HR 1.02, 95\% CI 1.003-1.034, $p=0.016$ ) and current cN-staging methods (HR 1.20, 95\% CI 0.978-1.48, $p=0.080$ ).

Conclusions Patients with discordant nodal staging on PET/CT and EUS represent an intermediate-risk group for overall survival. This finding was consistent in patients with cT3 tumours. These findings will assist optimum treatment decisions based upon perceived prognosis for each patient.

Key Points

- Clinicians are commonly faced with results of discordant nodal staging in oesophageal adenocarcinoma.

- There is a significant difference in overall survival between patients with negative, discordant, and positive lymph node staging.

- Patients with discordant lymph node staging between imaging modalities represent an intermediate-risk group for overall survival.
\end{abstract}

Keywords Oesophageal neoplasm $\cdot$ Lymph node $\cdot$ Neoplasm staging $\cdot$ Positron emission tomography $\cdot$ Endosonography

Electronic supplementary material The online version of this article (https://doi.org/10.1007/s00330-019-06642-6) contains supplementary material, which is available to authorized users.

Kieran Foley

Kieran.Foley@wales.nhs.uk; foleykg@ cardiff.ac.uk

1 Department of Clinical Radiology, University Hospital of Wales, Cardiff, UK

2 Wales Research and Diagnostic Positron Emission Tomography Imaging Centre (PETIC), Cardiff University, Cardiff, UK

3 Department of Clinical Radiology, Velindre University NHS Trust, Cardiff, UK

4 Division of Cancer \& Genetics, School of Medicine, Cardiff University, Cardiff, UK

\begin{tabular}{ll}
\multicolumn{2}{l}{ Abbreviations } \\
C-ve & Concordant negative nodal status \\
C+ve & Concordant positive nodal status \\
CI & Confidence intervals \\
CT & Computed tomography \\
cM-stage & Clinical M-stage \\
cN-stage & Clinical N-stage \\
cT-stage & Clinical T-stage \\
DC & Discordant nodal status \\
dCRT & Definitive chemoradiotherapy \\
EMR & Endoscopic mucosal resection \\
EUS & Endoscopic ultrasound \\
GOJ & Gastro-oesophageal junction \\
HR & Hazard ratio
\end{tabular}




\section{IQR Interquartile range \\ MDT Multi-disciplinary team \\ NACRT Neoadjuvant chemoradiotherapy \\ NACT Neoadjuvant chemotherapy \\ PET Positron emission tomography \\ UK United Kingdom}

\section{Introduction}

Oesophageal cancer is newly diagnosed in over 9000 people in the United Kingdom (UK) each year and predominately of adenocarcinoma cell type, with around 7 in 10 diagnosed at an advanced stage [1]. Radiological staging is central to management, planning, and prognosis, and usually involves a combination of computed tomography (CT), positron emission tomography combined with CT (PET/CT), and endoscopic ultrasound (EUS) [2].

Lymph node metastases are a major prognostic indicator in oesophageal cancer [3, 4]. Nodal assessment therefore is a key factor in radiological staging but the accuracy of these individual modalities is suboptimal $[5,6]$. EUS is generally regarded as the gold standard for assessment of regional lymph nodes, but controversy regarding the role of EUS in staging exists. Studies have shown limited benefits versus risk [7] whilst others suggest EUS can impact treatment decisions in 29\% of patients [8] and reduce edge of radiotherapy field relapses when EUS measurements are used to define gross tumour volume [9].

There is a lack of studies investigating the prognostic significance of nodal concordance between imaging modalities in oesophageal cancer staging. Diagnostic confidence is improved when a node has malignant characteristics on more than one imaging modality. The high specificity and positive predictive value compared with low sensitivity and negative predictive value of CT and PET/CT $[10,11]$ mean that a lymph node is often considered to be involved if malignant characteristics are demonstrated on multiple modalities.

However, clinicians face a difficult diagnostic conundrum in cases where there are discordant findings of malignancy in lymph nodes between different modalities. Important treatment decisions often hinge on the classification of nodal metastases on PET/CT and EUS examinations. In a previous study, Dhupar et al [12] reviewed 615 patients with oesophageal cancer from a single centre who underwent oesophagectomy for survival outcomes based on concordance of staging investigations for nodal disease. In summary, the study found that patients with discordance in nodal staging between imaging modalities had a better overall survival than patients with positively concordant nodal staging. However, more data is required to validate these findings.

Therefore, the aim of this study was to determine the prognostic significance of nodal concordance between PET/CT and EUS in oesophageal adenocarcinoma.

\section{Materials and methods}

Institutional review board approval was obtained for this study (reference 13//DMD5769). We performed a retrospective review of a prospectively collected database of patients with oesophageal adenocarcinoma in a regional upper GI cancer network comprising four health boards and eight different centres.

Consecutive patients $(n=420)$ were considered for this study. Inclusion criteria were patients with biopsyconfirmed adenocarcinoma of the oesophagus or gastrooesophageal junction (GOJ) who were staged with contrast-enhanced CT, PET/CT, and EUS between 2010 and 2016. Exclusion criteria were a histological cell type other than adenocarcinoma, those who did not have PET/ CT $(n=2)$ or EUS $(n=89 ; n=71$ because of M1 disease on PET/CT and $n=18$ due to non-traversable stenotic tumour), patients with missing TNM staging data $(n=17)$, and patients with missing survival data $(n=2)$. Following exclusion criteria application, 310 patients were included. During the study period, patients were staged according to TNM 7th edition [13]. Use of the TNM 8th edition [14] would not have altered stage groupings.

\section{Staging pathway}

Patients are usually diagnosed with oesophageal cancer following upper GI endoscopy and biopsy. Patients then undergo a contrast-enhanced $\mathrm{CT}$ of the thorax, abdomen, and pelvis to assess for distant metastases. If the patient was considered to have potentially curable disease after staging CT (i.e. absence of M1 disease), then more detailed staging with PET/CT and EUS was performed. EUS was not completed in patients with a non-traversable stenotic tumour and not performed in patients with confirmed M1 disease on PET/CT. The PET/CT and EUS protocols are available in the supplementary material.

\section{Clinical T-stage}

Following multi-disciplinary team (MDT) review, clinical Tstage (cT-stage) was assigned to each patient following consideration of the contrast-enhanced CT and EUS findings, with the latter being considered the most accurate modality for cT-stage [15].

\section{Definition of positive lymph node metastasis}

On PET/CT, nodes were classed as involved if identified on the CT component and showed FDG uptake appreciably higher than background values. No specific standardised uptake value was used to diagnose regional nodes because this decision is subjective and multi-factorial. Lymph 
nodes considered physiological or related to an alternative aetiology were excluded from the N-stage. On EUS, the criteria for malignant lymphadenopathy specified a hypoechoic pattern, spherical contour, distinct border, and a short-axis diameter of $6 \mathrm{~mm}$ or more. PET/CT and EUS $\mathrm{cN}$-staging were collected from the clinical radiology reports which were used to decide the subsequent treatment. Overall clinical N-stage (cN-stage) was assigned following MDT review after consideration of the combined CT, PET/ $\mathrm{CT}$, and EUS findings.

\section{Definition of concordance}

Three classifications were defined for this study. Nodal concordance was defined as either negative $(\mathrm{C}-\mathrm{ve})$ or positive $(\mathrm{C}+\mathrm{ve})$. $\mathrm{C}-\mathrm{ve}$ patients had cN0 disease on both $\mathrm{PET} / \mathrm{CT}$ and EUS and $\mathrm{C}+\mathrm{ve}$ patients had $\mathrm{cN}+$ disease on both modalities. Discordant patients (DC) had cN0 disease on one modality but not the other (Fig. 1). Further subgroups were constructed based on modality findings; PET/CT-ve:EUS+ve and EUS-ve:PET/CT+ve.

\section{Survival data}

The primary outcome of the study was overall survival, defined as the length of survival following diagnosis until death or date of last follow-up. Survival data was obtained from the Cancer Network Information System database. Patients are followed up at regular intervals following radical treatment, every 3 months for the first year and then 6-monthly thereafter for the next 4 years.

\section{Statistical analysis}

Descriptive statistics were expressed as frequency (percentage) for categorical variables and median (interquartile range (IQR)) for continuous variables. Differences between categorical variables and continuous variables were assessed using chi-square tests and MannWhitney $U$ tests, respectively. Median overall survival was estimated using the Kaplan-Meier life-table method [16]. Mean overall survival was calculated when median overall survival was not reached. Cumulative survival curves were generated and differences between groups evaluated with the log-rank test. The prognostic significance of cT-stage and $\mathrm{cN}$-stage were evaluated using this method. Hazard ratios were calculated with a Cox proportional hazards model and compared with the baseline group. A subgroup analysis for curative versus palliative treatment groups was pre-specified and performed separately. Multivariable analysis evaluated whether age at diagnosis, nodal concordance, or current $\mathrm{cN}$-staging methods were the better predictor of overall survival. Statistical analysis was performed using SPSS v23.0 (IBM). A $p$ value $<0.05$ was considered statistically significant.
Fig. 1 Clinical example of discordant radiological lymph node staging. A patient with a primary distal oesophageal adenocarcinoma had a 9-mm lymph node (white arrows) on (a) a contrast-enhanced CT and (b) a $\mathrm{PET} / \mathrm{CT}$ with minimally increased SUV (2.6) compared with background. An (c) EUS was performed which shows a malignant appearance $(8 \mathrm{~mm}$, round and hypoechoic), and a fine needle aspiration (FNA) was performed. The (d) FNA with papanicolaou stain at $\times 40$ magnification showed adenocarcinoma cells from the lymph node (large pleomorphic cells with prominent nucleoli in a cohesive group)

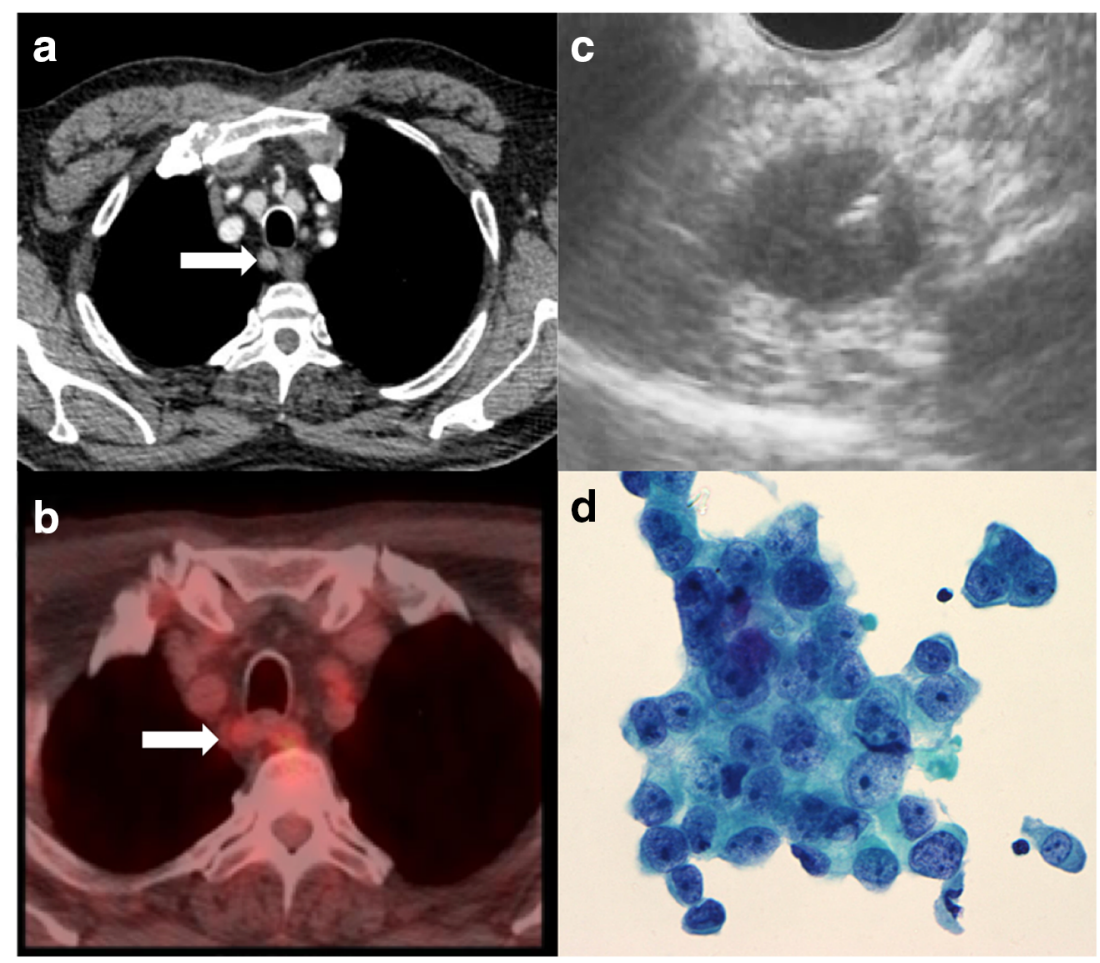




\section{Results}

The baseline characteristics of included patients are detailed in Table 1. The median age of the cohort was 66.0 years (IQR 59.5-72.5). The median overall survival was 23.0 months $(95 \%$ confidence intervals (CI) 18.73

Table 1 Baseline characteristics of patient cohort

\begin{tabular}{|c|c|}
\hline Clinical variable & Frequency $(\%)$ \\
\hline \multicolumn{2}{|l|}{ Gender } \\
\hline Male & $264(85.2)$ \\
\hline Female & $46(14.8)$ \\
\hline \multicolumn{2}{|l|}{ Tumour location } \\
\hline Oesophagus & $158(51.0)$ \\
\hline Mid oesophagus & $27(17.1)$ \\
\hline Distal oesophagus & $131(82.9)$ \\
\hline GOJ & $152(49.0)$ \\
\hline Siewert type I & $60(39.5)$ \\
\hline Siewert type II & $44(28.9)$ \\
\hline Siewert type III & $48(31.6)$ \\
\hline \multicolumn{2}{|l|}{ Grade of differentiation } \\
\hline Well & $21(6.8)$ \\
\hline Moderate & $97(31.3)$ \\
\hline Poor & $116(37.4)$ \\
\hline GX & $76(24.5)$ \\
\hline \multicolumn{2}{|l|}{ cT-stage } \\
\hline $\mathrm{T} 1$ & $29(9.4)$ \\
\hline $\mathrm{T} 2$ & $34(11.0)$ \\
\hline $\mathrm{T} 3$ & $202(65.2)$ \\
\hline $\mathrm{T} 4 \mathrm{a}$ & $41(13.2)$ \\
\hline $\mathrm{T} 4 \mathrm{~b}$ & $4(1.3)$ \\
\hline \multicolumn{2}{|l|}{ cN-stage } \\
\hline N0 & $132(42.6)$ \\
\hline N1 & $96(31.0)$ \\
\hline N2 & $54(17.4)$ \\
\hline N3 & $28(9.0)$ \\
\hline \multicolumn{2}{|l|}{ cM-stage } \\
\hline M0 & $310(100)$ \\
\hline \multicolumn{2}{|l|}{ Treatment } \\
\hline Radical & 222 (71.6) \\
\hline NACT & $94(42.3)$ \\
\hline dCRT & $56(25.2)$ \\
\hline Surgery alone & $48(21.6)$ \\
\hline NACRT & $20(9.0)$ \\
\hline EMR & $4(1.8)$ \\
\hline Palliative & $88(28.4)$ \\
\hline
\end{tabular}

$G O J$, gastro-oesophageal junction; $G X$, grade not assessed; $c T$-stage, clinical tumour stage; $c N$-stage, clinical regional nodal stage; $c M$-stage, clinical metastatic stage; $N A C T$, neoadjuvant chemotherapy; $d C R T$, definitive chemoradiotherapy; $N A C R T$, neoadjuvant chemoradiotherapy; $E M R$, endoscopic submucosal resection
27.29). One-, 2-, and 5-year overall survival rates were $73.5 \%(n=228 / 310 ; 95 \%$ CI $73.45-73.55), 48.4 \%(n=$ $150 / 310$; $95 \%$ CI $48.35-48.45)$, and $13.5 \%(n=42 / 310$; 95\% CI 13.44-13.55), respectively. The median follow-up was 63.0 months (95\% CI 57.97-68.04).

A large number of patients $(n=89)$ were initially excluded because of missing EUS data; therefore, comparison of baseline characteristics was performed in these patients. Age $(t=$ 1.518, mean difference 1.738 (95\% CI $-0.513-3.988)$, $p=$ $0.130)$, gender $\left(X^{2} 0.003\right.$, df $\left.1, p=0.957\right)$, and tumour location $\left(X^{2} 0.239\right.$, df $\left.1, p=0.625\right)$ were not significantly different between patient groups with and without EUS staging.

\section{Prognostic significance of nodal concordance between PET/CT and EUS}

The median overall survival for $\mathrm{C}-\mathrm{ve}, \mathrm{DC}$, and $\mathrm{C}+\mathrm{ve}$ patients were 43.0 months (95\% CI 33.22-52.78), 21.0 months (95\% CI 9.36-32.64), and 13.0 months (95\% CI 11.25-14.76), respectively. There was a significant difference in overall survival between groups $\left(X^{2}\right.$ 44.91, df 2, $p<0.001$ ) (Fig. 2). Furthermore, there were significant differences between $\mathrm{C}-\mathrm{ve}$ and $\mathrm{DC}$ groups $\left(X^{2}\right.$ 5.18, df $1, p=0.023)$ and DC and C+ve groups $\left(X^{2} 11.11\right.$, df $1, p=0.001)$. The hazard ratios for overall survival of $\mathrm{DC}$ and $\mathrm{C}+\mathrm{ve}$ patients compared with those of $\mathrm{C}-\mathrm{ve}$ patients overall were 1.46 (95\% CI 1.04-2.06) and 2.66 (95\% CI 1.97-3.60), respectively. This suggests that patients with discordant nodal staging between PET/CT and EUS represent an intermediate-risk group for overall survival.

\section{Prognostic significance of cT-stage and cN-stage}

In this cohort, cT-stage $\left(X^{2} 54.12, \mathrm{df} 4, p<0.001\right)$ and $\mathrm{cN}$ stage ( $X^{2} 48.85$, df $\left.3, p<0.001\right)$ were significantly associated with overall survival. The hazard ratios for overall survival of N1, N2, and N3 stages compared with those of N0 were 1.57 (95\% CI 1.14-2.15), 3.13 (2.19-4.49), and 2.60 (1.65-4.09), respectively. Survival statistics are presented for each cT-stage in Table 2.

There was a significant difference between $\mathrm{C}-\mathrm{ve}, \mathrm{DC}$, and C+ve patients staged with cT3 tumours $\left(X^{2} 10.19\right.$, df $2, p=$ 0.006 ) (Fig. 3). cT3 was significantly associated with overall survival but other cT-stages were not, likely due to the small numbers included. The hazard ratios for overall survival of $\mathrm{DC}$ and $\mathrm{C}+\mathrm{ve}$ patients compared with those of $\mathrm{C}-\mathrm{ve}$ patients with cT3 tumours were 1.21 (95\% CI 0.81-1.79) and 1.79 (95\% CI 1.23-2.61), respectively. No significant difference in overall survival was found between $\mathrm{C}-\mathrm{ve}$ and $\mathrm{DC}\left(X^{2}\right.$ 0.94 , df $1, p=0.33$ ), groups but there was a significant difference between DC and C+ve $\left(X^{2} 3.19\right.$, df $\left.1, p=0.048\right)$ groups, suggesting that DC patients with $\mathrm{cT} 3$ tumours have similar survival to $\mathrm{C}-$ ve patients. 
Fig. 2 KM plot showing cumulative survival curves for $\mathrm{C}-\mathrm{ve}, \mathrm{DC}$, and $\mathrm{C}+\mathrm{ve}$ patients $\left(X^{2}\right.$ 44.91, df $2, p<0.001)$

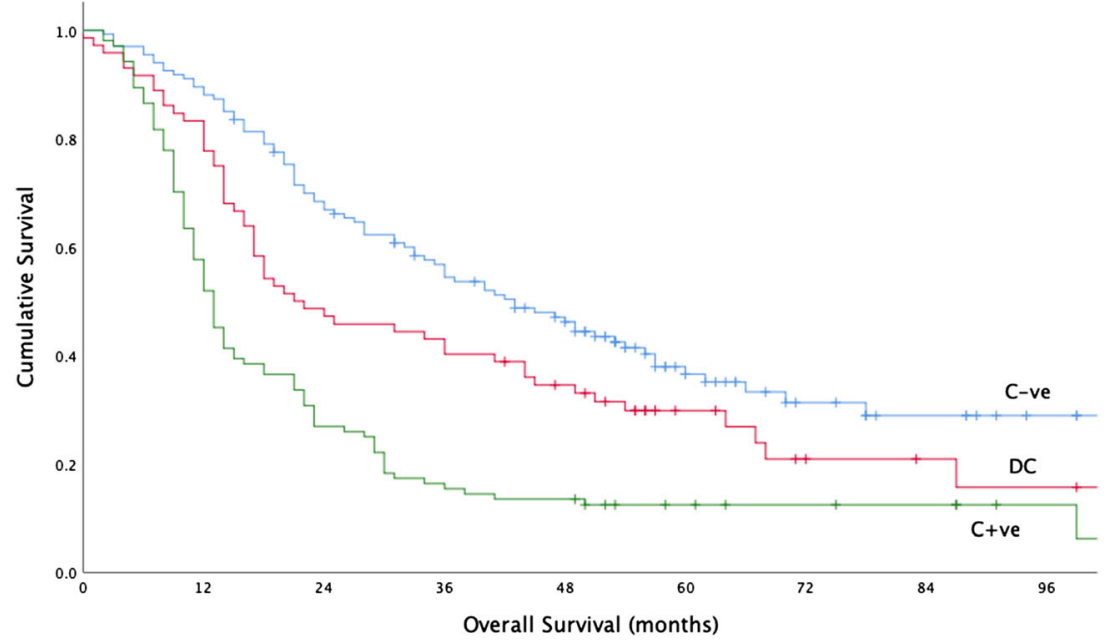

\section{Differences between PET/CT and EUS nodal staging}

The relationship between PET/CT and EUS N-staging was examined by creating two groups: (1) PET/CT-ve:EUS+ve and (2) EUS-ve:PET/CT+ve. In total, $16 / 310$ patients $(5.2 \%)$ had PET/CT cN+ and EUS cN0 disease. Conversely, 57/310 patients $(18.4 \%)$ had EUS $\mathrm{cN}+$ and PET/CT cN0 disease. There was a significant difference in frequency between these two groups $\left(X^{2} 97.29\right.$, df $\left.1, p<0.001\right)$. In addition, there were significant differences between $\mathrm{C}-\mathrm{ve}, \mathrm{PET} / \mathrm{CT}-\mathrm{ve}: \mathrm{EUS}+\mathrm{ve}$, EUS-ve:PET/CT+ve, and C+ve groups ( $X^{2}$ 50.99, df 3, $p<0.001$ ) (Fig. 4). The median overall survival for the EUS-ve:PET/CT+ve group was 14.0 months (95\% CI 12.70-15.30) and 34.0 months (95\% CI 13.92-54.08) for the PET/CT-ve:EUS+ve group. There was a significant difference between PET/CT-ve:EUS+ve and EUSve:PET/CT+ve groups $\left(X^{2} 6.50\right.$, df $\left.1, p=0.011\right)$ suggesting patients with PET/CT-ve:EUS+ve nodes had a better outcome, although the numbers in the PET/CT+ve:EUSve group were relatively low.

\section{Subgroup analysis}

With different treatment regimens included in this study, a subgroup analysis compared the prognostic significance of nodal concordance between patients treated with radical versus palliative treatments. There was a significant difference in overall survival between $\mathrm{C}-\mathrm{ve}, \mathrm{DC}$, and $\mathrm{C}+\mathrm{ve}$ nodal concordance when adjusting for treatment intent $\left(X^{2} 13.88\right.$, df $1, p=$ 0.001 ), demonstrating that the discordant group remained at intermediate risk in both radical and palliative settings. The median overall survival for patients treated with radical versus palliative intent was 37.0 months (95\% CI 28.77-45.23) and 12.0 months (95\% CI 10.04-13.97), respectively. Furthermore, there were no significant differences in overall survival $\left(X^{2}\right.$ 6.977 , df $4, p=0.137$ ) between radical treatment groups (neoadjuvant chemotherapy (NACT), definitive chemoradiotherapy (dCRT), surgery alone, neoadjuvant chemoradiotherapy (NACRT), and endoscopic mucosal resection (EMR)).

The hazard ratios for overall survival of DC and C+ve patients compared with those of $\mathrm{C}-\mathrm{ve}$ in patients treated with
Table 2 Comparison of cT-stage between negative concordance, discordance, and positive concordance groups

\begin{tabular}{|c|c|c|c|c|c|c|}
\hline T-stage & Concordance & Frequency $(\%)$ & Median OS (months) $(95 \% \mathrm{CI})$ & $X^{2}$ & $\mathrm{df}$ & $p$ value \\
\hline \multirow[t]{3}{*}{$\mathrm{T} 1(n=29)$} & $\mathrm{C}-\mathrm{ve}$ & $29(100)$ & *79.22 (64.85-93.59) & \multirow[t]{3}{*}{-} & \multirow[t]{3}{*}{-} & \multirow[t]{3}{*}{-} \\
\hline & $\mathrm{DC}$ & 0 & - & & & \\
\hline & $\mathrm{C}+\mathrm{ve}$ & 0 & - & & & \\
\hline \multirow[t]{3}{*}{$\mathrm{T} 2(n=34)$} & $\mathrm{C}-\mathrm{ve}$ & $25(73.5)$ & $40.0(25.31-54.69)$ & \multirow[t]{3}{*}{2.44} & \multirow[t]{3}{*}{2} & \multirow[t]{3}{*}{0.295} \\
\hline & $\mathrm{DC}$ & $5(14.7)$ & $67.0(67.0-67.0)$ & & & \\
\hline & $\mathrm{C}+\mathrm{ve}$ & $4(11.8)$ & $9.0(7.04-10.96)$ & & & \\
\hline \multirow[t]{3}{*}{$\mathrm{T} 3(n=202)$} & $\mathrm{C}-\mathrm{ve}$ & $71(35.1)$ & $33.0(24.74-41.26)$ & \multirow[t]{3}{*}{10.19} & \multirow[t]{3}{*}{2} & \multirow[t]{3}{*}{0.006} \\
\hline & $\mathrm{DC}$ & $61(30.2)$ & $22.0(7.79-36.21)$ & & & \\
\hline & $\mathrm{C}+\mathrm{ve}$ & $70(34.7)$ & $14.0(7.85-20.15)$ & & & \\
\hline \multirow[t]{3}{*}{$\mathrm{T} 4 \mathrm{a}(n=41)$} & $\mathrm{C}-\mathrm{ve}$ & $8(19.5)$ & $16.0(6.30-25.70)$ & \multirow[t]{3}{*}{4.29} & \multirow[t]{3}{*}{2} & \multirow[t]{3}{*}{0.117} \\
\hline & $\mathrm{DC}$ & $5(12.2)$ & $15.0(8.56-21.44)$ & & & \\
\hline & $\mathrm{C}+\mathrm{ve}$ & $28(68.3)$ & $12.0(10.52-13.48)$ & & & \\
\hline \multirow[t]{3}{*}{$\mathrm{T} 4 \mathrm{~b}(n=4)$} & $\mathrm{C}-\mathrm{ve}$ & $1(25.0)$ & $* 41.0(41.00-41.00)$ & \multirow[t]{3}{*}{3.34} & \multirow[t]{3}{*}{2} & \multirow[t]{3}{*}{0.188} \\
\hline & $\mathrm{DC}$ & $1(25.0)$ & $* 8.0(8.00-8.00)$ & & & \\
\hline & $\mathrm{C}+\mathrm{ve}$ & $2(50.0)$ & $* 6.5(5.52-7.48)$ & & & \\
\hline
\end{tabular}

*Mean OS; OS, overall survival; $X^{2}$, chi-square statistic; $d f$, degrees of freedom; $C$-ve, negative node concordance; $D C$, nodal discordance; $C+v e$, positive node concordance 
Fig. 3 Cumulative survival curves for $\mathrm{C}-\mathrm{ve}, \mathrm{DC}$, and $\mathrm{C}+\mathrm{ve}$ patients with cT3 tumours $\left(X^{2}\right.$ 10.19 , df $2, p=0.006$ )

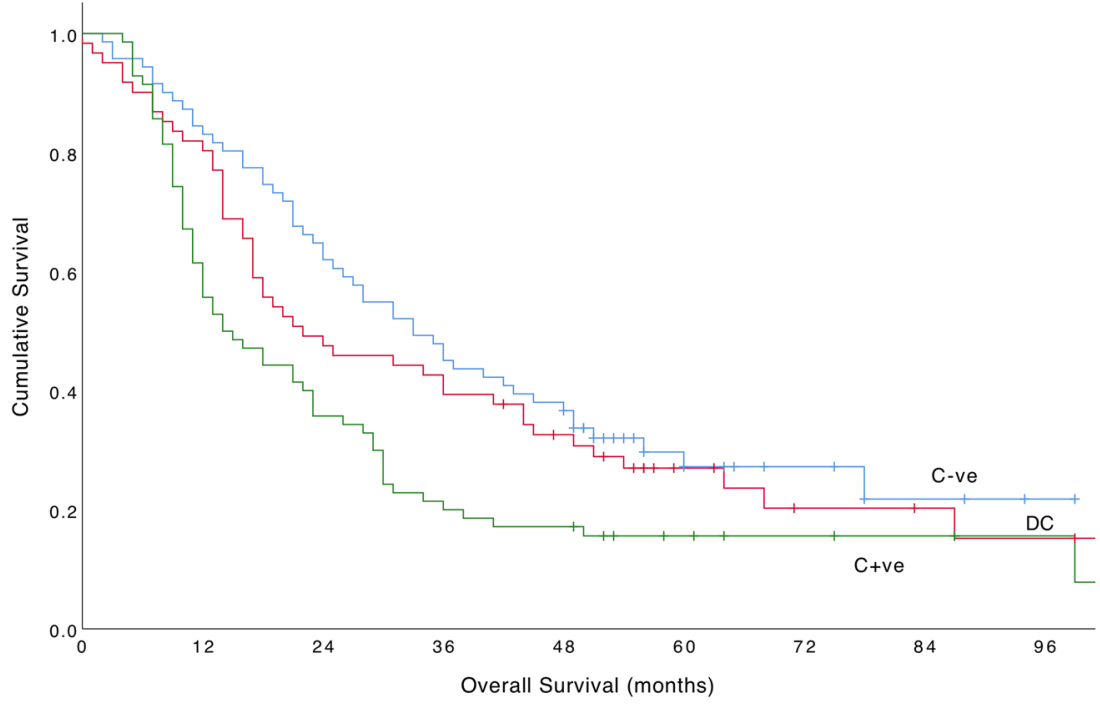

radical intent were 1.24 (95\% CI 0.84-1.84) and 1.75 (95\% CI 1.16-2.64), respectively. In palliative patients, the hazard ratios for overall survival of DC and C+ve patients compared with those of $\mathrm{C}-$ ve patients treated palliatively were 3.13 (95\% CI 1.46-6.67) and 2.38 (95\% CI 1.28-4.42), respectively. These results show that the overall survival of DC patients more closely matched $\mathrm{C}-$ ve patients when treated with radical intent, but the opposite effect was true when treated palliatively.

\section{Multivariable analysis}

On multivariable analysis, age at diagnosis, nodal concordance, and $\mathrm{cN}$-stage were entered into a multi-variable model. Nodal concordance was significantly and independently associated with overall survival (HR 1.44, 95\% CI 1.12-1.83, $p=0.004$ ) and performed better than age at diagnosis (HR 1.02, 95\% CI 1.003-1.034, $p=0.016$ ) and current $\mathrm{cN}$-staging methods (HR $1.20,95 \%$ CI $0.978-1.48, p=0.080$ ).

\section{Discussion}

This study has shown that patients with discordant nodal staging on PET/CT and EUS represent an intermediate-risk group for overall survival. This finding is important when deciding upon the optimum treatment decision based upon the perceived risk stratification for each patient [17].

Clinicians are commonly faced with results of discordant lymph node staging between imaging modalities. Accurate detection of lymph node metastases is important for staging and prognosis, and their detection changes treatment decisions. In this cohort, we have demonstrated the prognostic significance of $\mathrm{cT}$ - and $\mathrm{cN}$-stage. However, clinical ambiguity is introduced into decision pathways if two modalities (PET/CT and EUS) are discordant. This ambiguity can create diagnostic and management uncertainty for clinicians who must judge the most appropriate treatment considering the best interests of each patient. In such cases, a discordant lymph node is often considered likely to be metastatic given the incidence of
Fig. 4 Cumulative survival curves for $\mathrm{C}-\mathrm{ve}, \mathrm{PET} / \mathrm{CT}-\mathrm{ve}$ : EUS+ve, EUS-ve:PET/CT+ve, and C+ve patients $\left(X^{2} 50.99\right.$, df 3 , $p<0.001$ )

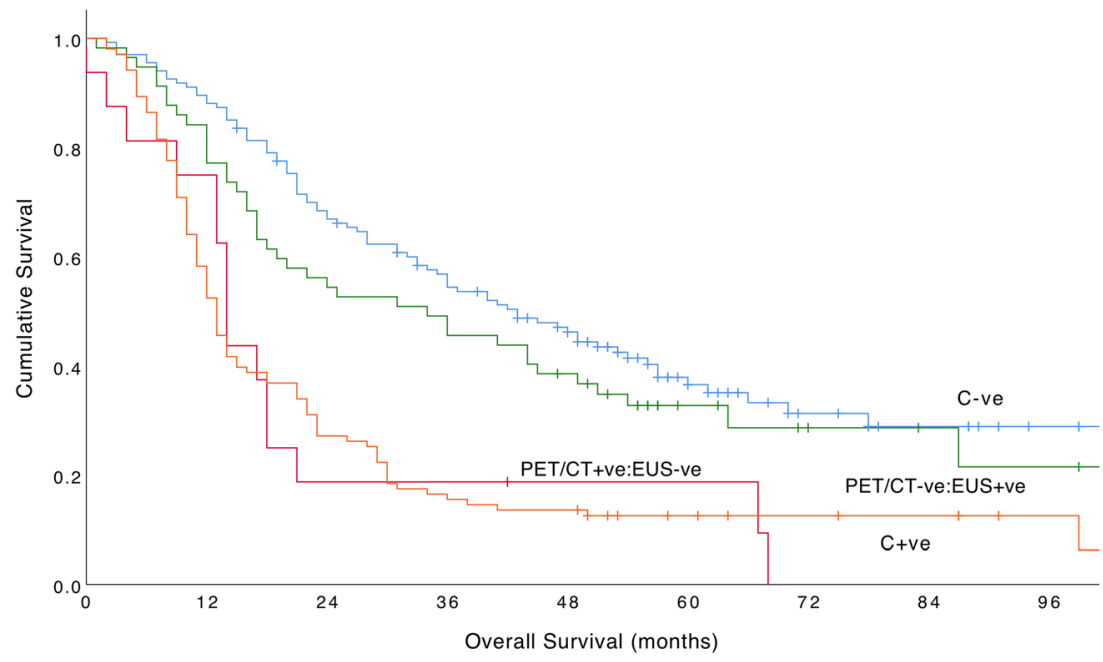


metastases with advanced cT-stage [3] and the higher specificity and positive predictive value of CT and PET [11].

These results are consistent with data from a cohort of oesophageal cancer patients who underwent oesophagectomy [12]. This study also described an intermediate-risk group comprising patients with discordant staging investigations, in which DC patients had better over survival than C+ve patients. Despite the findings of our current study, the literature surrounding the prognostic significance of discordant lymph node staging is sparse.

Importantly, this study has further shown the significant overall survival differences between $\mathrm{C}-\mathrm{ve}, \mathrm{DC}$, and $\mathrm{C}+\mathrm{ve}$ groups in patients with cT3 tumours. These data could be used to support clinical decisions in patients with cT3 tumours, which is the most common stage of oesophageal tumours at presentation [18]. Overall survival for patients with cT4 tumours was not found to be statistically significant between cTstage groups, but this is likely to be an effect of small patient numbers in this subgroup. Patients with nodal discordance had an overall survival probability more closely aligned to patients with $\mathrm{C}-\mathrm{ve}$ nodes, suggesting that in these cases, clinicians should place the findings in a wider clinical context and perhaps consider more radical treatment.

The subgroup analysis found that discordant nodal staging had a better prognosis in patients treated with radical intent but a worse prognosis in patients treated palliatively. These findings are likely to be biased by the retrospective nature of this study and influenced by the effects of treatment, which are broadly based on a number of clinical, physiological, radiological, and pathological factors. Endoscopic mucosal resection (EMR) is available for patients with limited early-stage disease. No survival benefit from EMR was demonstrated in this study, but only four EMR patients were included in this cohort. Fit, young patients may have been treated more aggressively than those with a significant number of comorbidities. In the latter cases, clinicians may have decided that the discordance added further uncertainty that the effects of radical treatment would be beneficial. This confounding bias cannot be adjusted for in retrospective studies, and these findings will need to be validated in prospective studies.

The number of patients classified with positive lymph nodes $(\mathrm{cN}+)$ is often higher on EUS than on PET/CT [15], and this trend was shown again here. PET imaging is limited in its ability to detect small and peri-tumoural lymph node metastases because of the relatively large spatial resolution and reliance on co-registration for anatomical definition [19]. In addition, the positive correlation between primary tumour and lymph node uptake means that metastases are less likely to be detected if the primary tumour demonstrates low FDG uptake. Overall, recent data has shown that the sensitivity of CT, PET/CT, and EUS is poor $(39.7 \%, 35.3 \%$, and $42.6 \%$, respectively) [5], which is consistent with data from other specialist oesophageal cancer centres [6] and different thoracic tumour sites such as nonsmall cell lung cancer [20].

Similarly, there was a significant difference in overall survival between PET/CT-ve:EUS+ve and EUS-ve:PET/CT+ve groups, suggesting that patients with PET/CT-ve:EUS+ve discordant nodes had a better outcome, although the numbers in the PET/CT-ve:EUS+ve were low. Overall, these results show that clinicians should refrain from instinctively concluding that a discordant lymph node is metastatic. False-positive rates of $\mathrm{CT}, \mathrm{PET} / \mathrm{CT}$, and EUS range between 15 and $30 \%$ for $\mathrm{cN}$-staging [10].

New methods to improve lymph node metastasis staging accuracy are required because radiological techniques alone are unlikely to improve sufficiently in the near future. A high proportion of micro-metastases ( $82 \%$ ) have been detected in normal-sized lymph nodes of patients with oesophageal cancer [5], and it is believed that micro-metastases are associated with a poorer clinical outcome [21], although the evidence is conflicting. At present, micro-metastases cannot be visualised on current imaging modalities.

The false-positive rates of each modality and high proportion of metastases highlight that lymph node staging should be considered within a multi-disciplinary context, with factors such as lymph node location and number, grade of primary tumour differentiation, and underlying tumour biology known to have prognostic significance [22].

\section{Strengths}

This study includes a large consecutive cohort of fully staged patients from a large regional upper GI cancer network serving a population of approximately 1.5 million. The overall survival data are robust and no patient was lost to follow-up. A comparison of cT-stage and radical versus palliative care treatment subgroups demonstrated that the prognostic significance of discordant lymph nodes was consistent.

\section{Limitations}

As discussed above, retrospective studies are likely to be hindered by confounding biases. Individual lymph nodes were not examined; rather, the $\mathrm{cN}$-stage between modalities was compared on a per-patient basis. Histopathological correlation was not possible in the majority of the cohort because relatively few patients are suitable for surgical resection. Contrast-enhanced CT data were not analysed in this study because it is known that the accuracy of CT $\mathrm{N}$-staging is poor and the PET/CT has a CT component which was used at the time of reporting to evaluate individual lymph nodes. Lastly, squamous cell carcinoma was not included because this study focussed on adenocarcinoma, the most prevalent histological cell type in European and North American countries [23]. 
In conclusion, this study has shown that patients with discordant nodal staging on PET/CT and EUS represent an intermediate-risk group for overall survival and have better survival rates than those with positively concordant lymph nodes. This finding was consistent in patients with cT3 tumours and is important when deciding upon the optimum treatment based upon the perceived prognosis for each patient. These results should be validated in prospective studies.

Acknowledgements The authors would like to thank Dr. Adam Christian (Department of Histopathology, University Hospital of Wales, Cardiff) for contributing the EUS-FNA image used in this article.

Funding information The authors state that this work has not received any funding.

\section{Compliance with ethical standards}

Guarantor The scientific guarantor of this publication is Dr. Kieran Foley.

Conflict of interest The authors of this manuscript declare no relationships with any companies whose products or services may be related to the subject matter of the article.

Statistics and biometry One of the authors (Dr. Kieran Foley) has significant statistical expertise.

Informed consent Written informed consent was waived by the Institutional Review Board.

Ethical approval Institutional Review Board approval was obtained (reference number 13//DMD5769).

Study subjects or cohorts overlap Some study subjects or cohorts have been previously reported in Foley KG, Hills RK, Berthon B, et al (2018) Development and validation of a prognostic model incorporating texture analysis derived from standardised segmentation of PET in patients with oesophageal cancer. Eur Radiol 28:428-436. https://doi.org/10.1007/ s00330-017-4973-y

This article investigated the prognostic significance of PET texture analysis. A similar cohort was used (patients with oesophageal cancer staged between 2010 and 2016, but nodal concordance between PET/CT and EUS was not included in this study and is a brand new research hypothesis).

\section{Methodology \\ - Retrospective \\ - Diagnostic or prognostic study \\ - Multi-centre study}

Open Access This article is licensed under a Creative Commons Attribution 4.0 International License, which permits use, sharing, adaptation, distribution and reproduction in any medium or format, as long as you give appropriate credit to the original author(s) and the source, provide a link to the Creative Commons licence, and indicate if changes were made. The images or other third party material in this article are included in the article's Creative Commons licence, unless indicated otherwise in a credit line to the material. If material is not included in the article's Creative Commons licence and your intended use is not permitted by statutory regulation or exceeds the permitted use, you will need to obtain permission directly from the copyright holder. To view a copy of this licence, visit http://creativecommons.org/licenses/by/4.0/.

\section{References}

1. Cancer Research UK (2019) Oesophageal cancer statistics. http:// www.cancerresearchuk.org/health-professional/cancer-statistics/ statistics-bycancer-type/oesophageal-cancer.

2. National Institute for Health and Clinical Excellence (NICE) (2018) NICE guideline [NG83]: Oesophago-gastric cancer: assessment and management in adults. https://www.nice.org.uk/ guidance/ng83

3. Kayani B, Zacharakis E, Ahmed K, Hanna GB (2011) Lymph node metastases and prognosis in oesophageal carcinoma-a systematic review. Eur J Surg Oncol 37:747-753

4. Davies AR, Gossage JA, Zylstra J et al (2014) Tumor stage after neoadjuvant chemotherapy determines survival after surgery for adenocarcinoma of the esophagus and esophagogastric junction. J Clin Oncol 32:2983-2990

5. Foley KG, Christian A, Fielding P, Lewis WG, Roberts SA (2017) Accuracy of contemporary oesophageal cancer lymph node staging with radiological-pathological correlation. Clin Radiol 72:e691e697

6. Bunting D, Bracey T, Fox B, Berrisford R, Wheatley T, Sanders G (2017) Loco-regional staging accuracy in oesophageal cancer-how good are we in the modern era? Eur J Radiol 97:71-75

7. Findlay JM, Bradley KM, Maile EJ et al (2015) Pragmatic staging of oesophageal cancer using decision theory involving selective endoscopic ultrasonography, PET and laparoscopy. Br J Surg 102: 1488-1499

8. Hulshoff JB, Mul VEM, de Boer HEM et al (2017) Impact of endoscopic ultrasonography on 18F-FDG-PET/CT upfront towards patient specific esophageal cancer treatment. Ann Surg Oncol 24: $1828-1834$

9. Button MR, Morgan CA, Croydon ES et al (2009) Study to determine adequate margins in radiotherapy planning for esophageal carcinoma by detailing patterns of recurrence after definitive chemoradiotherapy. Int J Radiat Oncol Biol Phys 73:818-823

10. van Vliet EP, Heijenbrok-Kal MH, Hunink MG et al (2008) Staging investigations for oesophageal cancer: a meta-analysis. $\mathrm{Br} \mathrm{J}$ Cancer 98:547-557

11. Shi W, Wang W, Wang J et al (2013) Meta-analysis of 18FDG PETCT for nodal staging in patients with esophageal cancer. Surg Oncol 22:112-116

12. Dhupar R, Correa AM, Ajani J et al (2014) Concordance of studies for nodal staging is prognostic for worse survival in esophageal cancer. Dis Esophagus 27:770-776

13. Sobin LH, Gospodarowicz MK, Wittekind CH (2009) TNM classification of malignant tumours, 7th edn. Wiley, New York

14. Sobin LH, Gospodarowicz MK, Wittekind CH (2017) TNM classification of malignant tumours, 8 th edn. Wiley, New York

15. Puli SR, Reddy JB, Bechtold ML et al (2008) Staging accuracy of esophageal cancer by endoscopic ultrasound: a meta-analysis and systematic review. World J Gastroenterol 14:1479-1490

16. Kaplan EL, Meier P (1958) Nonparametric estimation from incomplete observations. J Am Stat Assoc 53:457-481

17. Allum WH, Blazeby JM, Griffin SM et al (2011) Guidelines for the management of oesophageal and gastric cancer. Gut 60:1449-1472

18. Royal College of Surgeons of England (2013) National OesophagoGastric Cancer Audit (NOGCA). http://www.hscic.gov.uk/ catalogue/PUB11093/clin-audi-supp-prog-oesogast-2013-rep.pdf

19. Kinahan PE, Fletcher JW (2010) Positron emission tomography computed tomography standardized uptake values in clinical 
practice and assessing response to therapy. Semin Ultrasound CTMR 31:496-505

20. Frechet B, Kazakov J, Thiffault V et al (2018) Diagnostic accuracy of mediastinal lymph node staging techniques in the preoperative assessment of nonsmall cell lung cancer patients. J Bronchol Interv Pulmonol 25:17-24

21. Izbicki JR, Hosch SB, Pichlmeier U et al (1997) Prognostic value of immuno histochemically identifiable tumor cells in lymph nodes of patients with completely resected esophageal cancer. N Engl JMed 337:1188-1194
22. Frankell AM, Jammula S, Li X et al (2019) The landscape of selection in 551 esophageal adenocarcinomas defines genomic biomarkers for the clinic. Nat Genet 51:506-516

23. Arnold M, Soerjomataram I, Ferlay J, Forman D (2015) Global incidence of oesophageal cancer by histological subtype in 2012 . Gut 64:381-387

Publisher's note Springer Nature remains neutral with regard to jurisdictional claims in published maps and institutional affiliations. 